ORIGINAL ARTICLE

\title{
Survey of administration of medicines to pupils in primary schools within the London area
}

\author{
I C K Wong, T Awolowo, K Gordon, Y W Mo
}

Arch Dis Child 2004;89:998-1001. doi: 10.1136/adc.2003.047258

See end of article for authors' affiliations

.....................

Correspondence to: Dr lan C K Wong, Centre for Paediatric Pharmacy Research, School of Pharmacy, University of London, London WCIN 1AX, UK; ian.wong@ ulsop.ac.uk

Revised version received 6 April 2004

Accepted for publication 10 April 2004

Objective: To examine the policy, administration, and supervision of medicine administration in primary schools within the Greater London area (GLA).

Design: A prospective survey using postal questionnaires sent to 172 randomly selected primary schools within the GLA.

Participants: Head teachers of primary schools.

Results: Some $65 \%$ of head teachers replied. Less than $50 \%$ of responding head teachers had actually read the national guidelines Supporting Pupils with Medical Needs and only $30 \%$ of respondents were aware of other members of staff who had read the document. A total of $95 \%$ of respondents followed a policy/ procedure in caring for the medical needs of pupils. Over $80 \%$ of respondents had staff handling the pupils' medical needs, staff handling access to stored medicines, and prior arrangements for staff training. However, it is worrying that a quarter of the schools did not keep a written record of medicines given to children in schools. The majority of staff with responsibility for medicine administration in schools are support staff. The most encouraging findings were that for the majority of schools with children using the EpiPen and rectal diazepam, there were trained staff to administer these medicines.

Conclusions: The majority of schools had a policy in place to deal with medicine administration, although further work should be conducted to analyse the content of such policies. It is very important that training is directed at staff responsible for medicine administration and not just at teachers. Most schools were willing to administer rectal diazepam and EpiPen treatment in an emergency.

A ccording to the General Household Survey in England, $20 \%$ of children between the ages of 5 and 15 have a longstanding illness. ${ }^{1}$ The number of children of school age receiving medical treatment is rising and the treatment is becoming more complex. Children need to take prescribed medicines during school time for various reasons, such as asthma, ${ }^{2}$ epilepsy, ${ }^{3}$ diabetes, ${ }^{4}$ severe allergy, ${ }^{5}$ and attention deficit hyperactivity disorder. ${ }^{6}$ There have been suggestions that children with medical needs are excluded from school because insufficient support is provided by schools. ${ }^{7}$ For example, MENCAP (a UK disability charity) has reported that a child who required rectal diazepam was unable to attend school because the school was unable to administer the drug when required. ${ }^{8}$ Considering that children spend most of the day at school, there is no doubt that schools should play an important role in managing the medicines of children with longstanding illnesses. It is important that measures be implemented to optimise the management and administration of medicines in this vulnerable group. ${ }^{8}$ However, some parents have pointed out that there seems to be a lottery approach in whether or not schools aid the provision of medicines to children during school hours. The main issues are whether protocols exist, who administers the medicines, and who decides whether the medicines are given. ${ }^{9}$

Unfortunately, very little research has been conducted on the management and administration of medicines in schools, despite recommendations from the Department of Health (DoH) and Department of Education and Skills (DfEs) document, Supporting Pupils with Medical Needs. ${ }^{10}$ Only two studies have been identified and both studied the use of asthma medication in schools. ${ }^{11}{ }^{12}$

The concept of this study was conceived during a National Service Framework for Children (NSFC) Medicine Group meeting; however, we were unable to investigate all the issues discussed during the meeting due to the general limitations of the questionnaire use in this study.

\section{OBJECTIVE}

The objective of this study was to examine the policy, administration, and supervision of medicine administration in primary schools within the Greater London area (GLA).

\section{METHODOLOGY}

\section{Development of the questionnaire}

The main items of the questionnaire were developed following a discussion amongst the members of the NSFC Medicines Group and a literature review.

The questionnaire covered the following issues:

- Knowledge of the policy document issued by the DoH and DfES.

- Policy/procedure followed in caring for the medical needs of pupils.

- Staff involved in handling the medical needs of children and medicine administration.

- How information regarding administration of medicines to pupils is received and documented.

- Training.

The pre-pilot questionnaire was sent to a qualified school teacher and an educational psychologist for evaluation and amendments were made based on their comments. The prepilot questionnaire was then sent to two head teachers in Barnet (an area in London) to test the content validity.

Abbreviations: DfEs, Department of Education and Skills; DoH, Department of Health; GLA, Greater London area; NSFC, National Service Framework for Children 
Following their responses, additional modifications were made before conducting the pilot study.

\section{The pilot study}

The pilot questionnaire was sent to the head teacher of one randomly selected school of each London borough (32 schools) for their comments in order to assess the face validity. A reminder was sent to the non-responders after 3 weeks. The questionnaire was then modified to form the final questionnaire.

\section{Data collection for the main study}

A list of all primary schools (total of 1565) in all boroughs of the GLA was obtained from the website of the DfES ${ }^{13}$ and 172 schools were selected using a random table. ${ }^{14}$ The main questionnaire was sent to the head teacher of each school. A reminder questionnaire was sent to non-responders after 4 weeks.

\section{Data analysis}

All data collected were coded, processed, and analysed using SPSS for Windows version 11.0. The data were entered by TA and then checked and cleaned by YM. Analysis was conducted by IW, TA, and KG. The pilot data were excluded.

\section{Ethics}

At the time of study, according to the UK Office of Central Ethics Committee's guidelines, the study did not require ethics committee approval. ${ }^{15}$

\section{RESULTS}

The response rate to main questionnaire was $65 \%$ (111/172). The results of the responses to all closed questions and the three open questions are presented in table 1.

\section{DISCUSSION}

School documents and policies regarding supporting pupils with medical needs and medication administration

The DoH/DfES ${ }^{10}$ document represents a rare but welcome example of interdepartmental collaboration between health and education. ${ }^{7}$ However, our results were very disappointing, as approximately one third of respondents were unaware of the document and less than $50 \%$ of all schools had actually read it. This situation is not unique to London as Jones et al also reported that only $18 \%$ of head teachers had used the document. ${ }^{11}$ Question A 5 in table 1 shows that $17 \%$ of respondent schools had their policies drawn up either by the Local Education Authority, the health and safety committee of the local borough, the Primary Care Trust, or the local school medical service. It is very likely these organisations had used the DoH/DfES guidelines without the knowledge of the head teachers and this could partly explain why some head teachers are unaware of the national document.

We would urge the DoH and DfES to use the current heightened awareness of medicines and children, created by the NSFC, as an opportunity to update the national document and also to remind head teachers of its usefulness and significance.

Some $95 \%$ of respondents followed a policy/procedure in caring for the medical needs of the pupils. However, studies assessing the different policies in schools are needed to provide an insight into the medicine administration practices within schools.

\section{Responsibility for the medical needs of pupils and medication access}

Some $92 \%$ and $94 \%$ of respondents indicated that they had at least one member of staff dealing with pupils' medical needs and handling access to stored medicines, respectively. It is interesting that the staff responsible are mainly support staff including secretaries and lunch time supervisors. Training in medical needs and medication related matters should be targeted at the staff responsible for such matters rather than being limited to teaching staff.

The use of written health care plans for individual pupils can enhance care and it was encouraging to see that approximately $50 \%$ of respondents had individual care plans for children with diabetes, asthma, or epilepsy.

\section{Acceptance of instructions from parents and record keeping}

Approximately $16 \%$ of schools accepted verbal instruction and $24 \%$ of schools did not keep a written record of the medicine administered to pupils. Both practices increase the risk of medication errors and should be discouraged. Other important issues, such as the location and conditions of medicine storage in school, the methods of sending medicines to school, and the administration of medicines during school trips, should be further investigated in any future studies.

\section{Staff training in medicine management and administration}

Some $86 \%$ of schools already had arrangements for staff training regarding medical needs. It was interesting to discover that $49 \%$ of respondents believed that sufficient training was given to in-service teachers in helping pupils administer their medicines, but only $9 \%$ believed sufficient training was given as part of the Postgraduate Certificate of Education (PGCE), an official teaching qualification in the UK. Indeed the results are echoed by findings of the DoH. ${ }^{9}$ Further studies should be conducted of both in-service teachers and students undertaking the PGCE to identify their training needs in the areas of medicine management and administration.

Only $39 \%$ of respondents indicated that they would be interested in having a pharmacist provide training for staff in the management and administration of medicines in schools. This response rate is consistent with that reported in previous studies and reviews ${ }^{11}{ }^{16}$ showing that schools are not generally supportive of the idea. Pharmacists have the potential to improve the use of medication in schools, not only by providing training and advice, but also by providing new services such as dispensing medicines in special suitably labelled "lunchtime" containers, which could be left at school to reduce the risk of errors and improve compliance. Furthermore, pharmacists can advise clinicians and parents on alternative dosing regimens, formulations, or treatments to avoid administration of medication during school hours, for example slow release methylphenidate.

\section{Administration of intimate and invasive treatment in emergency}

This is probably the most contentious topic in the use of medicines in schools; some staff were understandably reluctant in volunteering to administer intimate or invasive treatment such as rectal diazepam or the EpiPen because of the nature of the treatment or fears about the associations of abuse of children.

Our results in this area were very encouraging; 83 schools had children currently prescribed the EpiPen and 80 had trained staff to administer it. Similarly, 15 had children on rectal diazepam and 12 had trained staff to administer it. This highlighted that most respondent schools were well prepared to administer rectal diazepam and EpiPen treatment in an emergency. 


\section{Table 1 Summary of responses to questions}

B) Responsibility for the medical needs of pupils and medication access

1) Does your school have a designated member of staff who handles the medical needs of the pupils? ( $n=107$ respondents) 2) Who are the designated staff responsible for medical needs $† \ddagger$ ( $n=98$ respondents)

3) Is there a member of staff who handles access to stored medicines? ( $n=109$ respondents)

4) Who are the designated staff responsible for handling access

to stored medicines $† \ddagger$ ( $n=100$ respondents)

5) Does your school keep written health care plans for the individual child with epilepsy? ( $\mathrm{n}=105$ respondents)

6) Does your school keep written health care plans for the individual child with diabetes? ( $\mathrm{n}=105$ respondents)

7) Does your school keep written health care plans for the individual child with asthma? ( $\mathrm{n}=108$ respondents)

\section{C) Acceptance of instructions from parents and records keeping}

1) Does your school accept verbal instruction from parents regarding the administration of medicines in school? ( $n=107$ respondents) 2) Does your school have a written record of medicine administered to pupils? ( $n=108$ respondents)

\section{D) Staff training}

1) Does your school provide training to staff about the medical needs of pupils? ( $n=108$ respondents)

2) In your opinion, do you think there is sufficient training for in-service teachers to help pupils in administering their medicines while they are in school? ( $\mathrm{n}=98$ respondents)

3) In your opinion, do you think that the PGCE programmes provide sufficient training to equip future teachers in helping pupils to administer required medicines? ( $n=102$ respondents)

4) Would you be interested in having a pharmacist to train staff regarding the administration of medicines to children in school? ( $n=102$ respondents)

Response

Number

Percent

Yes
No
Yes
No
Yes
No
Yes
No
School governing body
Special Education Needs
Co-ordinator
Local Education Authority
Health and safety
committee of local borough
Local school medical service
DoH/DfES guideline
Primary Care Trust

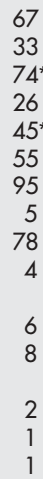

Yes

No

Supporting staff§

Teaching staff-

Head teacher/deputy

head teacher

First aider

School nurse

Yes

No

Supporting staff§

Teaching staff-

Head teacher/deputy

head teacher

First aider

School nurse

Not applicable

Yes

No

Not sure

Not applicable

Yes

No

Not sure

Not applicable

Yes

No

Not sure

$\begin{array}{rr}73 & 67 \\ 36 & 33 \\ 52 & 74 \\ 18 & 26 \\ 33 & 45 \\ 40 & 55 \\ 05 & 95 \\ 5 & 5 \\ 76 & 78 \\ 4 & 4 \\ & \\ 6 & 6 \\ 8 & 8 \\ 2 & \\ 1 & 2 \\ 1 & 1 \\ 1 & 1\end{array}$

No

Yes 


\begin{tabular}{|c|c|c|c|}
\hline Question & Response & Number & Percent \\
\hline \multicolumn{4}{|l|}{ E) Administration of intimate and invasive treatment in emergency } \\
\hline 5) Are there any children in your school who have been prescribed & Yes & 83 & 75 \\
\hline \multirow{2}{*}{ the EpiPen? ( $n=110$ respondents) } & No & 25 & 23 \\
\hline & Not sure & 2 & 2 \\
\hline \multirow{3}{*}{$\begin{array}{l}\text { 6) Does your school have trained staff to administer the EpiPen to } \\
\text { children in an emergency? ( } n=98 \text { respondents) }\end{array}$} & Not applicable & 5 & 5 \\
\hline & Yes & 80 & 82 \\
\hline & No & 13 & 13 \\
\hline \multirow{3}{*}{$\begin{array}{l}\text { 7) Are there any children in your school who have been prescribed } \\
\text { rectal diazepam? ( } n=108 \text { respondents) }\end{array}$} & Yes & 15 & 14 \\
\hline & No & 91 & 84 \\
\hline & Not sure & 2 & 2 \\
\hline \multirow{3}{*}{$\begin{array}{l}\text { 8) Does your school have trained staff to administer the rectal diazepam } \\
\text { to children in an emergency? ( } n=90 \text { respondents) }\end{array}$} & Not applicable & 32 & 36 \\
\hline & Yes & 12 & 13 \\
\hline & No & 46 & 51 \\
\hline
\end{tabular}

${ }^{*} 47 \%$ of the original cohort; ${ }^{*} 30 \%$ of the original cohort.

tOpen question. The answers were categorised by the investigators (one teacher and one pharmacist).

¥Some schools reported more than one designated person as responsible for the task.

§Supporting staff includes secretary, administrative officer, office manager, welfare officer/assistant, and lunch time supervisor.

-Teaching staff include: teacher, special education needs co-ordinator (SENCO), SENCO assistant, learning support assistant, and teaching/class assistant.

Not applicable, question does not apply to respondent; PGCE, Postgraduate Certificate in Education (UK official teaching qualification).

\section{CONCLUSION}

The results show that the majority of schools had a policy in place to deal with medicine administration. Further work should be conducted to analyse the content of such policies, particularly since one third of the responding head teachers were not aware of the national guidelines and less than half had actually read them. The majority of staff with responsibility for medicine administration in schools are support staff and it is very important that training is directed at these staff and not just at teachers. The majority of schools with

\section{Information box}

1) $20 \%$ of children between the ages of 5 and 15 in England have a longstanding illness.

2) Some parents have pointed out that schools seem to have a "lottery approach" to children taking medicines.

3) Sometimes children are unable to attend schools because schools are unable to administer the EpiPen or rectal diazepam when required in emergency.

4) Very little research has been conducted on the management and administration of medicines in schools.

5) Less than $50 \%$ of head teachers had actually read the national guidelines Supporting Pupils with Medical Needs and this may be the cause of the "lottery approach".

6) A quarter of the schools did not keep a written record of medicines given to children in the schools; this practice increases the risk of medication errors.

7) Some $49 \%$ of head teachers believed that sufficient training was given for in-service teachers but only $9 \%$ believed there was sufficient training for Postgraduate Certificate of Education students regarding the administration of medicines to children in schools.

8) The majority of staff with responsibility for medicine administration in schools are support staff and it is very important that training is directed at these staff and not at just teachers.

9) The majority of schools with children using the EpiPen and rectal diazepam had trained staff to administer them. children using the EpiPen and rectal diazepam had trained staff to administer them.

\section{ACKNOWLEDGEMENTS}

The authors would like to thank the head teachers who replied to the questionnaire and the members of NSFC Medicines External Working Group for their comments.

\section{Authors' affiliations \\ I C K Wong, T Awolowo, K Gordon, Y W Mo, School of Pharmacy, University of London, London, UK}

Dr Wong's post is funded by a Department of Health Public Health Career Scientist Award.

Conflict of interest: none declared.

This study does not represent the opinions of the Department of Health or NSFC Medicines External Working Group.

\section{REFERENCES}

1 Office of National Statistics. General household survey. London: HMSO, 1998.

2 Anderson HR, Butland BK, Strachan DP. Trends in prevalence and severity of childhood asthma. BMJ 1994;308:1600-4.

3 Camfield P, Camfield C. Childhood epilepsy: what is the evidence for what we think and what we do? J Child Neurol 2003;18(4):272-87

4 Anon. Using medicines in school. Drug Ther Bull 1994;32(1 1):81-3.

5 Anon. Adrenaline for anaphylaxis. Drug Ther Bull 1994;32:19-21.

6 Leffert N, Susman A. Attention deficit hyperactivity disorder in children. Curr Opin Pediatr 1993;5:129-33.

7 Bannon MJ, Ross EM. Administration of medicines in school: who is responsible? BMJ 1998;316:1591-3.

8 MENCAP. Don't count me out. The exclusion of children with a learning disability from education because of health needs. MENCAP Campaign report. http://www.mencap.org.uk/download/dont_count_me_out.pdf (accessed 13/08/04).

9 Department of Health. National service framework consultation event relating to children's medicines: listening and responding to parents and young people. http://www.dh.gov.uk/assetRoot/04/03/27/85/04032785.pdf (accessed 02/09/04).

10 Department for Education \& Employment (DFEE) and Department of Health. Supporting pupils with medical needs: a good practice guide. London 1996. http://www.teachernet.gov.uk/_doc/4422/Med.pdf (accessed 02/09/04).

11 Jones J, Millson D, Black P. Asthma medication management in primary schools. Pharm J 2000;265:R53.

12 Fillmore EJ, Jones N, Blankson JM. Achieving treatment goals for school children with asthma. Arch Dis Child 1997;77:420-2.

13 Department for Education and Skills. Primary school (key stage 2) performance tables. http://www.dfes.gov.uk/performancetables/ primary_02.shtml (accessed 13/08/04).

14 Altman DG. Practical statistics for medical research. 1st ed. London: Chapman and Hall/CRC, 1991:540-4.

15 Central Office for Research Ethics Committees. Frequently asked questions. http://www.corec.org.uk/applicants/help/faqs.htm\#a (accessed 02/09/ 04).

16 Reutzel TJ, Patel R, Myers MA. Medication management in primary and secondary schools. J Am Pharm Assoc 2001;41(1):67-77. 